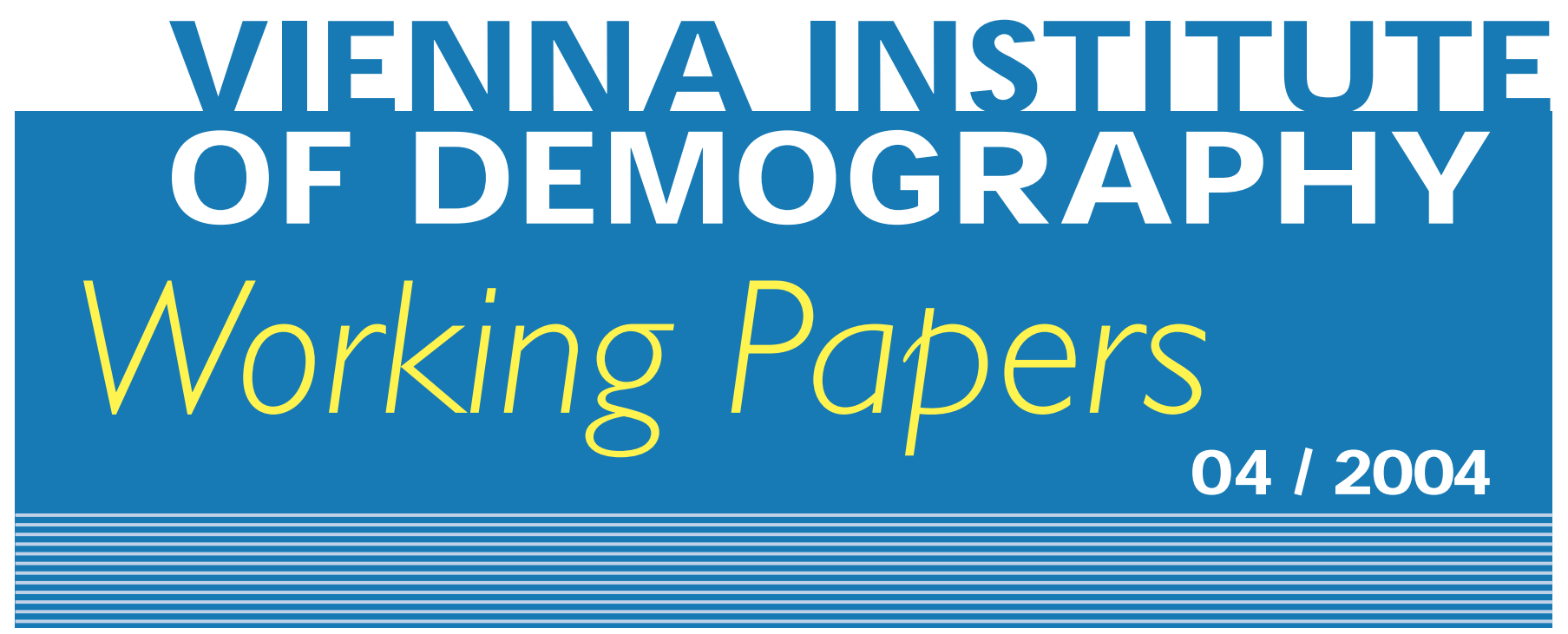

Franz Schwarz

Analysis of Inequalities in Waiting Time at the

Visit to the Physician using the

Regression M odeling for Duration Data

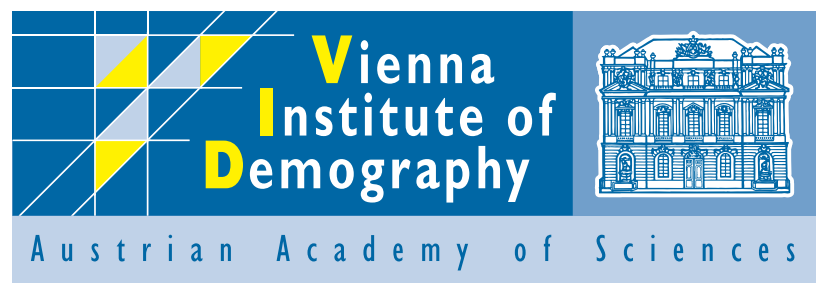

Vienna Institute of D emography

Austrian A cademy of Sciences

Prinz Eugen-Strasse 8-10 · A-1040Vienna · A ustria

E-Mail: vid@ oeaw.ac.at

W ebsite: www.o eaw.ac.at/vid 


\title{
Analysis of Inequalities in Waiting Time at the Visit to the Physician using Regression Modeling for Duration Data
}

\author{
Franz Schwarz ${ }^{1}$
}

Vienna, Dezember, 2004

\begin{abstract}
When we visit our physician, we usually have to wait for a more or less long duration until we are called into the doctors' office. This study reveals inequalities in the waiting time at the visit to the general practitioner by using multiplicative intensity regression analysis, which is frequently used for modeling time to event data. In general, people with higher education have a higher efficiency to reduce waiting time. Further, Austrians show a higher efficiency than foreigners. With regard to health-related factors, those with better health and less frequent consultations have also a higher efficiency to reduce waiting time. It also matters where people live. Those living in rural areas in general wait longer, and furthermore, the longer the journey from home to the doctors' practice takes, the longer is the waiting time.
\end{abstract}

\footnotetext{
${ }^{1}$ This article was partly written while the Author stayed at the Max Planck Institute for Demographic Research, and partly at the Vienna Institute of Demography. Views or opinions expressed in this paper are attributable to the Author and do not necessarily reflect those of the Institutes where the article was written. E-mail: franz.schwarz@oeaw.ac.at.
} 


\section{Introduction}

When we visit our physician, we usually have to wait for a more or less long time until we can enter the doctors' office. At this point, the question occurs whether certain groups of people, in average, wait longer/shorter. Since humans are social beings that show different interaction behavior with other individuals, we can expect such inequalities in waiting time in most areas where individual behavior and social status is relevant.

With regard to visits at the physician, there are several reasons for inequalities in observed waiting time, namely individual behavior, discrimination, demographic reasons, and measurement errors. Individual behavior means that particular groups of people are more efficient in reducing waiting time, i.e. they may take initiative regarding making appointments, or they may convince the receptionist of the urgency of their disorder or their shortage in time. Discrimination is experienced in all spheres of life, so why not at the visit to the physician. Social discrimination regards not only socioeconomic status but other circumstances too, such as the discrimination of people with foreign nationality. However, we might rather speak of preferential treatment than of discrimination, i.e. priority is given to those with a high occupational position since i.e. one may assume that these people are in lack of time. It also matters where the patients live. The provision with physicians is better in cities than in rural areas, which may lead to shorter waiting time. Further, long distances to the doctor cause more waiting time since people usually tend to be on time for an appointment, and therefore, depart some time earlier. In case that people provide just an approximation of their experienced waiting time, a serious measurement problem occurs, namely that different groups of people might have a different perception in waiting time. For instance, very ill people might feel a particular waiting time longer than healthy people do. We are not able to deal with this problem, since we do not have the actual time but only the estimated time stated by the patients themselves. However, we are able to control for state of health or whether people consult their doctor because of a disorder or a checkup.

The examination of the efficiency to reduce waiting time of different social groups is the main issue of the present study. Here, factors such as gender, education, and nationality will be taken into account. However, we won't be able to distinguish clearly between behavioral inequalities and preferential treatment. As far as geographical differences are concerned, municipality type and the distance to the practice will be taken into account. Inequalities in waiting time of people with different self reported state of health are also of interest. These health-related covariates serve additionally to distinguish between healthy and ill people of a particular social status. 


\section{Data and Method}

The data source for the analysis is the Austrian microcensus dated September 1999. The microcensus is a panel household survey carried out quarterly in one percent of all dwellings (around 30,000) in Austria, whereby each quarter one eight of the sample is replaced. In the dwellings, all individuals are interviewed by means of face-to-face interviews. The survey consists of a mandatory basic program and a voluntary special program. The consistent basic program collects socio-demographic data about the social, vocational and educational situation of the respondents. In a separate household sheet, information about the dwelling is collected. The voluntary special program, on the other hand, addresses changing topics such as living standard, career, traveling, leisure time, vacations, etc. In September 1999, the special program was a survey on health behavior, state of health, and health care utilization. Out of 58,745 respondents of the mandatory basic program 45,572 responded to the microcensus' voluntary special program. In this special program, respondents were also asked about their waiting time at the last visit to the physician, whereof 28,791 respondents had a visit to the general practitioner.

In this study, the socioeconomic and demographic influence variables are gender, educational attainment, municipality type, citizenship, and distance to the doctor's office. The variable educational attainment is a straightforward and established choice for modeling behavioral differences of socioeconomic groups. Other indicators would be job status, or salary/income (which is not available here). The job status of employees, however, is usually in strong relation to their education. When using educational attainment as a proxy of the socioeconomic status, one has to consider that those still attending school have to be excluded from the analyses or to be kept as a separate category; otherwise this would bias the results. Therefore, only those aged 25 and older were included into the analyses, which leaves us with a sample size of 22,616 respondents. Additional to socio-demographic covariates, health related factors are taken into account. Table 2.1 provides an overview of the relevant variables. These variables are all measured and fixed at the time of interview.

This study uses a multiplicative intensity model with a piece-wise constant baseline hazard function to measure efficiency in reducing waiting time. A multiplicative intensity piecewise constant model explores, similar to Cox-regression, the effects of several variables on time to event, or survival. However, while Cox-regression delivers just regression coefficients or relative hazards, a piecewise constant model estimates the baseline hazard function for predefined time intervals additionally. In our case, time to event is from entering the doctor's practice to treatment. Waiting time is estimated by patients themselves and measured in minutes; however, durations of $5,10,15,30, \ldots$ minutes were preferably stated by the respondents. To account for this fact, time intervals were created, where these peaks are about in the middle of the intervals. Table 
2.1 shows the intervals for the variable duration. Observations above 195 minutes were omitted, since one can assume that a waiting time longer than 3 hours is out of the ordinary duration, which are due to miss-reporting and due to reasons that we don't know.

Table 2.1: Descriptive statistics (respondents aged 25 and older, unweighted sample)

\begin{tabular}{|c|c|c|c|}
\hline Variable & Category & Cases & $\%$ \\
\hline \multirow[t]{8}{*}{ Duration of waiting time } & $0-7$ & 2,780 & 9.7 \\
\hline & $8-12$ & 3,205 & 11.2 \\
\hline & $13-17$ & 3,261 & 11.3 \\
\hline & $18-45$ & 11,364 & 39.6 \\
\hline & $46-75$ & 5,442 & 19.0 \\
\hline & $76-135$ & 2,189 & 7.6 \\
\hline & $136-195$ & 345 & 1.2 \\
\hline & $196-360$ & 137 & 0.5 \\
\hline \multirow[t]{2}{*}{ Gender } & male & 12,627 & 55.7 \\
\hline & female & 10,041 & 44.3 \\
\hline \multirow[t]{4}{*}{ Education } & basic & 8,270 & 36.5 \\
\hline & vocational & 10,759 & 47.5 \\
\hline & highschool/college & 2,834 & 12.5 \\
\hline & university & 805 & 3.5 \\
\hline \multirow[t]{3}{*}{ Municipality type } & rural & 16,803 & 74.1 \\
\hline & urban & 3,665 & 16.2 \\
\hline & Vienna & 2,200 & 9.7 \\
\hline \multirow[t]{2}{*}{ Citizenship } & Austrian & 21,945 & 96.8 \\
\hline & foreign & 723 & 3.2 \\
\hline \multirow[t]{6}{*}{ Home-to-practice time } & $0-5$ & 3,352 & 14.9 \\
\hline & $6-15$ & 9,233 & 41.0 \\
\hline & $16-30$ & 7,655 & 34.0 \\
\hline & $31-60$ & 1,817 & 8.1 \\
\hline & $61-120$ & 352 & 1.6 \\
\hline & $121-240$ & 105 & 0.5 \\
\hline \multirow[t]{4}{*}{ Self reported state of health } & very good & 4,672 & 21.0 \\
\hline & good & 9,332 & 42.0 \\
\hline & fair & 6,318 & 28.4 \\
\hline & bad/very bad & 1,926 & 8.6 \\
\hline \multirow[t]{5}{*}{ Diseased in the last year } & never & 8,862 & 40.3 \\
\hline & once & 8,404 & 38.2 \\
\hline & twice & 2,946 & 13.4 \\
\hline & three times & 1,085 & 4.9 \\
\hline & more than three times & 689 & 3.1 \\
\hline \multirow[t]{2}{*}{ Chronically ill } & no & 12,622 & 59.0 \\
\hline & yes & 8,781 & 41.0 \\
\hline \multirow{2}{*}{$\begin{array}{l}\text { In need of care at time of } \\
\text { interview }\end{array}$} & no & 19,344 & 90.8 \\
\hline & yes & 1,965 & 9.2 \\
\hline \multirow{3}{*}{$\begin{array}{l}\text { Consultations in the last } 12 \\
\text { months prior to the interview }\end{array}$} & one & 5,697 & 25.4 \\
\hline & two & 4,569 & 20.3 \\
\hline & more than two & 12,211 & 54.3 \\
\hline \multirow[t]{2}{*}{ Reason for last consultation } & checkup & 11,047 & 51.3 \\
\hline & disorder & 10,499 & 48.7 \\
\hline
\end{tabular}


The intensity, or efficiency to reduce waiting time respectively, is estimated by the regression equation

$$
\lambda(t ; \mathbf{z})=\lambda_{0}(t) \cdot \mathrm{e}^{\boldsymbol{\beta}^{\prime} \mathbf{z}}=\lambda_{0}(t) \cdot \mathrm{e}^{\beta_{1} z_{1}} \cdot \mathrm{e}^{\beta_{2} z_{2}} \cdot \ldots \cdot \mathrm{e}^{\beta_{k} z_{k}},
$$

where $t$ is the time to event, $\mathbf{z}$ is a vector of explanatory variables and the $\beta$ 's are the unknown regression parameters. $\lambda_{0}(t)$ denotes the baseline hazard function that is obtained when $\mathbf{z}$ is a vector of zeros. The relative risks $\exp \left(\beta_{i}\right)$ act multiplicative on $\lambda_{0}(t)$ and describe the risk change in the base line hazard associated with a variable. ${ }^{2}$

\section{Results}

Table 3.1 and Table 3.3 show relative risks, or, in other words, the efficiency to reduce waiting time. The first three models concern socioeconomic and demographic covariates. The first model considers just educational attainment. Here, all categories are significant different from the reference category, showing an increasing order in the relative risks from lower to higher education. This means that the higher people's education is, the higher is the probability to get into the doctors office during waiting time. Considering a shorter waiting time as efficiency, we can say that the higher education is the more efficient people are. The second model includes the covariates gender, municipality type and nationality, and the third model includes additionally age. The inclusion of these variables serves to control for confounding, since different population structures lie behind the educational groups. At the same time, however, we are able to explain the effect of these additional covariates.

As we can see in model 2, the effect on education decreases very little when we include gender, municipality type and citizenship. Most efficient in reducing their waiting time are academics. Model 2 shows that their efficiency is $43 \%$ higher than it is of those with basic education. The efficiency of those with high school or college graduation is $21 \%$ higher, and of those with apprenticeship is $9 \%$ higher than of those with basic education. With regard to municipality type, in rural areas the relative risk to get into the doctor's office during waiting time is significant lower $(8 \%)$ than for those living in urban areas or in Vienna. It is also of relevance whether people are foreigners or Austrians; here foreigners show a 7\% lower efficiency to get into surgery during waiting time. The variable gender shows no effect on waiting time. The inclusion of the variable age in model 4 doesn't improve the model significantly either, which can be

\footnotetext{
${ }^{2}$ For the interpretation of the regression parameters, the percentage change in the risks, $100\left(\mathrm{e}^{\beta}-1\right)$, is a useful notation.
} 
tested by a Log-Likelihood test ${ }^{3}$. Hence, we do not observe a significant effect on waiting time regarding age.

Table 3.1: Relative risks for getting into the doctor's office

\begin{tabular}{|c|c|c|c|c|c|}
\hline & Model 1 & Model 2 & Model 3 & Model 4 & Model 5 \\
\hline \multicolumn{6}{|l|}{ Gender } \\
\hline female & & 1 & 1 & 1 & 1 \\
\hline male & & 1.01 & 1.02 & 1.02 & 1.02 \\
\hline \multicolumn{6}{|l|}{ Education } \\
\hline basic & 1 & 1 & 1 & 1 & 1 \\
\hline vocational & $1.10 * * *$ & $1.09 * * *$ & $1.08^{* * *}$ & $1.07^{* * *}$ & $1.06^{* * *}$ \\
\hline high school/college & $1.23^{* * *}$ & $1.21^{* * *}$ & $1.21^{* * *}$ & $1.19^{* * *}$ & $1.16^{* * *}$ \\
\hline university & $1.48^{* * *}$ & $1.43^{* * *}$ & $1.42^{* * *}$ & $1.40^{* * *}$ & $1.35^{* * *}$ \\
\hline \multicolumn{6}{|l|}{ Municipality type } \\
\hline rural & & $0.92 * * *$ & $0.92 * * *$ & $0.90^{* \star *}$ & $0.92^{* * *}$ \\
\hline urban & & 1 & 1 & 1 & 1 \\
\hline Vienna & & 1.00 & 1.00 & 0.96 & 1.00 \\
\hline \multicolumn{6}{|l|}{ Citizenship } \\
\hline Austrian & & 1 & 1 & 1 & 1 \\
\hline foreign & & 0.93 * & $0.93^{* *}$ & 0.93 * & 0.93 * \\
\hline \multicolumn{6}{|l|}{ Age group } \\
\hline $25-39$ & & & 1 & 1 & 1 \\
\hline $40-54$ & & & 1.02 & 1.02 & $1.06 * * *$ \\
\hline $55-69$ & & & 0.98 & 0.99 & $1.05^{* *}$ \\
\hline $70+$ & & & 1.01 & 1.04 * & $1.11^{* * *}$ \\
\hline \multicolumn{6}{|l|}{ Home-to-practice time } \\
\hline $0-5$ & & & & 1 & \\
\hline $6-15$ & & & & $0.80^{* * *}$ & \\
\hline $16-30$ & & & & $0.73^{* * *}$ & \\
\hline $31-60$ & & & & $0.63^{* * *}$ & \\
\hline $61-120$ & & & & $0.51^{* * *}$ & \\
\hline $121-240$ & & & & $0.32^{* * *}$ & \\
\hline \multicolumn{6}{|l|}{ State of health } \\
\hline very good & & & & & 1 \\
\hline good & & & & & $0.88^{* * *}$ \\
\hline fair & & & & & $0.78^{* \star *}$ \\
\hline bad/very bad & & & & & $0.79^{* \star *}$ \\
\hline-2 log-likelihood & $63,840.6$ & $63,811.6$ & $63,805.5$ & $62,718.2$ & $62,354.5$ \\
\hline Degrees of freedom ${ }^{4}$ & 10 & 14 & 17 & 22 & 20 \\
\hline
\end{tabular}

It is important to be aware of interactions between covariates. Table 3.2 shows such interactions between municipality type and education, standardized for gender, citizenship and age, as well as the interaction between municipality type and citizenship, standardized for gender, education, and age. We can observe the strongest effect of educational attainment in urban areas, followed by rural areas, ending with Vienna. For instance, in urban areas, the differences in the risks between high school/college graduates and those with basic education is $35 \%$, in rural region this groups show a

3 A Log-Likelihood-Test tests whether the inclusion of additional variables improves a model significantly using the fitting information -2Log-Likelihood. The difference between two values of -2LL is chi-square distributed: $\chi^{2}=-2 L L_{0}-\left(-2 L L_{1}\right)$ with $d f_{1}-d f_{0}$ degrees of freedom.

${ }^{4}$ The models also include a baseline intensity with seven estimated parameters 
difference in the risks of $1.19 / 0.99$ that is $20 \%$, and in Vienna, it is just $1.21 / 1.16$ that is $4 \%$. When we look at inequalities between Austrians and foreigners, no effect can be observed in rural areas and in Vienna, but in towns in the provinces of Austria only. Here, the difference in the risks results in a value of $20 \%$. According to the outcomes of Table 3.2, the assumption of multiplicative intensities is violated to some extent.

Table 3.2: Interaction between municipality type and education, standardized for gender, citizenship and age, and interaction between municipality type and citizenship, standardized for gender, education, and age.

\begin{tabular}{|c|c|c|c|c|c|c|}
\hline \multirow[b]{2}{*}{ Municipality } & \multicolumn{4}{|c|}{ Education * } & \multicolumn{2}{|c|}{ Citizenship ** } \\
\hline & basic & vocational & college & university & Austrian & foreign \\
\hline rural & 0.99 & 1.06 & 1.19 & 1.47 & 0.91 & 0.89 \\
\hline urban & 1 & 1.19 & 1.35 & 1.51 & 1 & 0.80 \\
\hline Vienna & 1.16 & 1.17 & 1.21 & 1.40 & 0.99 & 0.98 \\
\hline
\end{tabular}

* -2log-likelihood $=63,791,8, \mathrm{df}=23 ;{ }^{* *}$-2log-likelihood $=63,800,4 \mathrm{df}=19$

We know that those living in rural areas have a longer distance to the doctor's practice. Since people usually tend to be on time for an appointment, and consequently, depart some time earlier, it is reasonable that people wait longer if they live farther away. Therefore, a longer waiting time in rural regions might be a result of the distance. However, when we include the home-to-practice time (model 4), the changes in the relative risks for the variable municipality type are negligible. Model 4 also allows us to consider the relevance of the time that people need to get from their home or work place to the doctor's practice. It shows that home-to-practice time determines waiting time to a great extent; namely, the longer home-to practice time the longer is waiting time. For instance, for those whose journey is one to two hours the efficiency to reduce waiting time is around $50 \%$ lower than for those whose journey is just 5 minutes or less.

The next six models (5-11) include health related variables additionally to the socioeconomic and demographic covariates. In model 5 , the risk effects in the covariate state of health appear in decreasing order, namely the worse the health status is the lower is efficiency. People, who assessed their health as bad or very bad, show a $21 \%$ lower efficiency than those with a good or very good state of health. This may be due to the fact that ill people are more likely to visit their doctor without making an appointment; as a result, efficiency decreases, or waiting time increases respectively. The same applies to all other alternative covariates that concern state of health. A more objective way to measure health than asking people how they feel, is to ask them about how many times they visited a physician or how often they were ill in the last year, or whether they are chronically ill. At this point, we observe for the frequency of being diseased in model 6 once more a decreasing order in the efficiency. I.e., for those who were more than three times ill in the year prior to the interview, the efficiency is $24 \%$ lower than for those who were never ill. The same applies to those who are chronically ill (model 9), where the efficiency is $10 \%$ lower. The covariate frequency of illness was checked for interaction with the variable education. With regard to number of illnesses, 
the gradient in the efficiency applies to all educational groups to a similar extent. Hence, the multiplicative assumption is fulfilled.

Table 3.3: Relative risks for getting into the doctor's office with health related covariates

\begin{tabular}{|c|c|c|c|c|c|c|}
\hline & Model 6 & Model 7 & Model 8 & Model 9 & Model 10 & Model 11 \\
\hline \multicolumn{7}{|l|}{ Gender } \\
\hline female & 1 & 1 & 1 & 1 & 1 & 1 \\
\hline male & 1.02 & 1.01 & 1.01 & 1.02 & 1.02 & 1.02 \\
\hline \multicolumn{7}{|l|}{ Education } \\
\hline basic & 1 & 1 & 1 & 1 & 1 & 1 \\
\hline vocational & $1.08^{* * *}$ & $1.08^{* * *}$ & $1.07^{* * *}$ & $1.08^{* * *}$ & $1.08^{* * *}$ & $1.08^{* *}$ \\
\hline high school/college & $1.20 * * *$ & $1.20 * * *$ & $1.19^{* * *}$ & $1.20^{* * *}$ & $1.21^{* * *}$ & $1.21^{* * *}$ \\
\hline university & $1.42^{* \star *}$ & $1.40^{* * *}$ & $1.39^{* * *}$ & $1.42^{* * *}$ & $1.45^{* * *}$ & $1.45^{* * *}$ \\
\hline \multicolumn{7}{|l|}{ Municipality type } \\
\hline rural & $0.91^{* * *}$ & $0.92 * * *$ & $0.93^{* * *}$ & $0.92 * * *$ & $0.93^{* * *}$ & $0.92 * * *$ \\
\hline urban & 1 & 1 & 1 & 1 & 1 & 1 \\
\hline Vienna & 0.99 & 1.00 & 1.02 & 1.00 & 1.00 & 0.99 \\
\hline \multicolumn{7}{|l|}{ Citizenship } \\
\hline Austrian & 1 & 1 & 1 & 1 & 1 & 1 \\
\hline foreign & 0.94 & $0.92^{* *}$ & 0.92 ** & 0.94 & $0.92 * *$ & $0.93 * *$ \\
\hline \multicolumn{7}{|l|}{ Age group } \\
\hline $25-39$ & 1 & 1 & 1 & 1 & 1 & 1 \\
\hline $40-54$ & 1.02 & 1.04 ** & 1.03 * & 1.01 & 1.02 & 1.01 \\
\hline $55-69$ & 0.97 & 1.01 & 1.01 & 0.96 ** & 0.96 * & 0.96 * \\
\hline $70+$ & 1.01 & $1.05^{\star *}$ & $1.06^{* * *}$ & 0.99 & 0.97 & 0.97 \\
\hline \multicolumn{7}{|l|}{ Frequency of diseases } \\
\hline never & 1 & & & & & 1 \\
\hline once & $0.90^{* * *}$ & & & & & $0.90 * * *$ \\
\hline twice & $0.85^{* * *}$ & & & & & $0.85^{* * *}$ \\
\hline Three times & $0.82^{* * *}$ & & & & & $0.80 * * *$ \\
\hline more than three times & $0.76^{* * *}$ & & & & & $0.74^{* * *}$ \\
\hline \multicolumn{7}{|l|}{ Chronically ill } \\
\hline no & & 1 & & & & \\
\hline yes & & $0.90^{* * *}$ & & & & \\
\hline \multicolumn{7}{|l|}{ Consultations } \\
\hline one & & & 1 & & & \\
\hline two & & & $0.86^{* * *}$ & & & \\
\hline three and more & & & $0.83^{* * *}$ & & & \\
\hline \multicolumn{7}{|l|}{ Reason for consultation } \\
\hline checkup & & & & 1 & & \\
\hline disorder & & & & $0.92 * * *$ & & \\
\hline \multicolumn{7}{|l|}{ In need of care } \\
\hline no & & & & & 1 & 1 \\
\hline yes & & & & & $1.15^{* * *}$ & $1.20^{* * *}$ \\
\hline-2 log-likelihood & $61,592.9$ & $60,143.0$ & $62,881,9$ & $60,261.8$ & $59,838.3$ & $58,401,6$ \\
\hline Degrees of freedom & 21 & 18 & 19 & 18 & 18 & 22 \\
\hline
\end{tabular}

One may assume that people who visit their doctor frequently are considered regular customers, and therefore, have some privileges regarding waiting time. This, however, does not apply, because people, who have to take visits to the doctor more often, are usually sicker than those who visit their doctor just once a year for a checkup. Model 8 shows that people with more consultations have a significant lower efficiency. For those with three and more consultations the reduction in efficiency results in a value of $17 \%$. It also matters whether people consult their physician because of a disorder or a 
checkup. Model 9 shows an $8 \%$ lower efficiency for those whose reason is a disorder. Again, those who suffer on a disorder are more likely to go instantaneously to the doctor, whereas those who have a checkup are more likely to make an appointment. Finally, we take a look at the efficiency of those who are in need of care in model 10. At this point, we have a $15 \%$ higher efficiency for those in need of care. One may argue that those in need of care are usually sicker. When we, therefore, distinguish between the healthy and the less healthy people, we might perhaps increase the efficiency of people in need of care. This is proven when we include the frequency of being ill in the analysis. To be precise, the efficiency raises from $15 \%$ to $20 \%$.

Besides the relative risks, a piecewise constant model delivers additionally the baseline hazard function, shown in Figure 3.1 for model 3. The constant risks for the predefined time interval are actually not realistic. However, with regard to the fact that waiting time is stated by the patients themselves, a step function is advantageous since the enormous peaks in waiting times of $5,10,15,30,60, \ldots$ minutes are smoothed out. We have to consider that these peaks would be unrealistic; it is more realistic to say that a person that stated a waiting time of 60 minutes, waited actually within a certain interval around 60 minutes. The step function gives us an idea of the shape of the hazard function. In the beginning the probability to get into the doctors office increases quickly, and it decreases slowly after a maximum in the risks between a waiting time of 45 to 75 minutes.

Figure 3.1: Baseline hazard to model 3

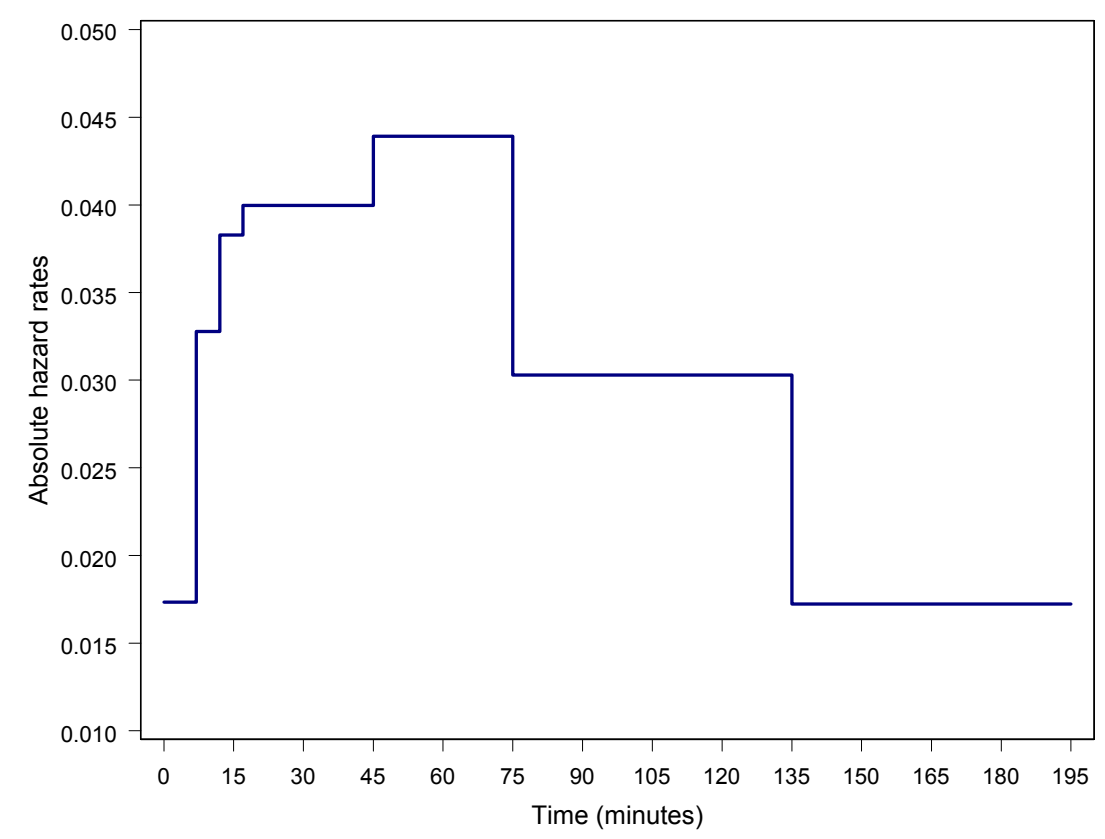




\section{Conclusion}

The study shows a significant higher efficiency to reduce waiting time for those with higher education. In comparison to those with basic education, the efficiency is around $40 \%$ higher for university graduates, about $20 \%$ higher for high school and college graduates, and around $10 \%$ higher for those with vocational education. We do not know the exact reason for these inequalities; however, the inequalities may be traced back to the circumstance that those with higher education may take more initiative regarding making appointments. The same applies to foreigners, who show a 7\% lower efficiency. There might also be some preferential treatment of those with higher socioeconomic status be involved, however, we are not able to prove this.

With regard to demographic differences, people who live in rural areas have a longer waiting time. This may be the result of the higher provision with physicians in urban areas. Furthermore, the longer the journey from home to the physicians practice, the longer is waiting time, which is reasonable since people usually tend to be on time for an appointment, and therefore, depart some time earlier.

Another important role regarding waiting time play health related factors. The worse the state of health is, the more often people are ill, and the more frequent they consult their doctor the lower is efficiency in reducing waiting time. Waiting time is also extended when people are chronically ill or when they consult their physician because of a disorder instead of heaving a checkup. This may be due to the fact that ill people are more likely to visit their doctor without making an appointment; as a result, efficiency decreases, or waiting time increases respectively. This, however, does not apply to people who are in need of care. At this point, we may assume that the helping person arranges appointments and/or the receptionist prioritizes the treatment of these people.

The inclusion of health related covariates, at the same time, allows us to distinguish between healthy and less healthy people of different socioeconomic status. However, the resulting changes in the risk of the socio-demographic covariates are negligible when we include such health related covariates in the model.

\section{References}

Allison, Paul (1985): Event History Analysis: Regression for Longitudinal Event Data. Sage Publications.

Hosmer, David W. \& Lemeshow, Stanley (1999): Applied Survival Analysis. Regression Modeling for Time to Event Data. John Wiley \& Sons.

Teachman, Jay D. (1982): Methodological issues in the analysis of family formation and dissolution. Journal of Marriage and the Family. Volume 44, Issue 4: p 1037-1053. 


\section{VIENNA INSTITUTE OF DEMOGRAPHY}

\section{Working Papers}

Winkler-Dworak, Maria. 2003. Food Security, Fertility Differentials and Land Degradation in Sub-Saharan Africa: A Dynamic Framework. VID Working Papers 01/2003. Vienna Institute of Demography.

Frejka, Tomas and Jean-Paul Sardon. 2003. Fertility Austria: Past, Present and the Near Future. VID Working Papers 02/2003. Vienna Institute of Demography.

Sanderson, Warren C., Sergei Scherbov, Brian C. O'Neill, and Wolfgang Lutz. 2003. Conditional probabilistic population forecasting. VID Working Papers 03/2003. Vienna: Vienna Institute of Demography.

Fliegenschnee, Katrin, Anne Goujon and Wolfgang Lutz. 2004. Neue demographische Szenarien zur Zukunft der Evangelischen Kirche in Österreich. VID Working Papers 01/2004. Vienna: Vienna Institute of Demography.

Engelhardt, Henriette. 2004. Fertility Intentions and Preferences: Effects of Structural and Financial Incentives and Constraints in Austria. VID Working Papers 02/2004. Vienna: Vienna Institute of Demography.

Prskawetz, Alexia, Tomas Kögel, Warren C. Sanderson and Sergei Scherbov. 2004. The Effects of Age Structure on Economic Growth: An Application of Probabilistic Forecasting to India. VID Working Papers 03/2004. Vienna: Vienna Institute of Demography.

Schwarz, Franz. 2004. Analysis of Inequalities in Waiting Time at the Visit to the Physician using Regression Modeling for Duration Data. VID Working Papers 04/2004. Vienna: Vienna Institute of Demography. 